\title{
DESIGN FOR TEACHER TRAINING - TO FACILITATE STUDENT TEAMS WORKING WITH REAL-LIFE SUSTAINABILITY CHALLENGES
}

\author{
S. C. Nilsson ${ }^{\otimes}$ and M. Norell Bergendahl \\ KTH Royal Institute of Technology, Sweden \\ $\triangle$ suni@kth.se
}

\begin{abstract}
The aim of the study is to contribute to the knowledge on how to develop students' skills and capabilities required when addressing complex societal challenges in practice. In this paper we are investigating the design and implementation of a teacher training module focusing on improving teacher's ability to facilitate students' teams learning and collaboration skills. The feedback and learning from the design and implementation of the module at universities in Botswana, Kenya and Sweden is presented and discussed in this paper.
\end{abstract}

Keywords: design education, sustainability, teamwork, challenge-driven education

\section{Introduction}

On a global scale, $20 \%$ of the world's population continue to exploit more than $80 \%$ of its resources and climate change is agreed to be an extreme threat to our civilization, and the UN Agenda 2030 points out many of the challenges (UN, 2015). As a consequence, there is an urgent need to raise questions about the future and how innovative solutions to development issues, that are not only solving the pressing needs of the present, but are enhancing the ability of future generations to meet new complex challenges. The role of academia and higher education to develop education programs that better prepare and equip students to address the challenges is critical. Within the academic field of sustainability there is an emerging consensus regarding what the most important competences for students are in order to innovatively address sustainability issues (Wiek et al., 2011). New skills and capabilities to enable students to work in multi-functional and cultural teams is one area that is considered critical since it is well recognized that complex societal challenges cannot be solved by a single discipline or nation. To meeting the demand on developing the innovation capacity required, a key component is to develop programs and courses that enable students to work in teams addressing real life sustainability challenges. Literature related to challenge-driven education (CDE), shows that allowing student teams to work in open-ended projects involving real life challenges has the potential to increase students' capabilities to address complex challenges in an innovative and sustainable way (e.g. Rosén et al., 2018, Högfeldt et al., 2018, Rådberg et al., 2018). However, to ensure this potential is realised, less traditional ways of teaching and supporting such student teams need to be implemented where the ability to facilitate collaboration and learning in teams becomes essential. As a consequence, the skills of the teachers involved in these projects also need to be further developed to support them to act more like facilitators or coaches rather than as taking on their traditional lecturer role. In this paper we are investigating the design and implementation of a teacher training focusing on 
improving teacher's ability to facilitate students' teams learning and collaboration skills, named Facilitation and Collaboration for Innovation and Learning (FaCoIL). The FaCoIL has so far trained more than 60 teachers in Botswana, Kenya and Sweden and the feedback and learning from the design and implementation of the training is presented and discussed in this paper. The training is developed within a higher education teacher training program aiming to support university teacher's capabilities to design and implement courses where real-life challenges are addressed by student teams from different engineering disciplines and cultures. The teacher training program is part of an initiative referred to as the Global Development Hub (GDH) at KTH, Royal Institute of technology, Sweden, which has the aim to develop students' innovative skills by integrating global challenges into the engineering curriculum (Norell Bergendahl et al., 2018).

The aim of the paper is to provide some insights on how teacher's ability to facilitate learning and collaboration in student teams that are addressing complex societal challenges can be improved. The design of the teacher training is presented and the feedback from participating teachers is analysed to identify critical elements. The paper ends with a discussion on the implications when designing a teacher training program facilitating student teams to work with real-life sustainability challenges.

\section{Teaching skills for student teams addressing real-life challenges}

UN Agenda 2030 requires changes in education and teaching to develop students' skills to handle substantially more complex and open-ended student team projects (UNESCO, 2017). Challengedriven education $(\mathrm{CDE})$, is a concept that when implemented in higher education to some extent resembles "real problem-based learning" as defined by Kolmos et al., (2008) which can be considered linked to the strive to bring the practical side of engineering design back into the engineering curriculum (Dutson et al., 1997). The learning is built around open-ended student projects where the development of solutions requires knowledge and skills beyond that of a single discipline (e.g. Magnell and Högfeldt 2015, Rosén et al., 2018). CDE in this paper is used as a core element when designing project-based courses involving multi-disciplinary and multi-cultural teams of students in close interaction with various external stakeholders, targeting complex societal and global sustainability challenges. The courses (can be on both bachelor or master level) are aiming to have both actual impact through developed or proposed solutions and through the development of students' innovative skills by the methods, processes and networks that they are making use of. Engaging and interacting with many different stakeholders play an important role since the challenges are delivered by them- and not defined by a university teacher as is the case in the majority of courses in higher education - and because they are receivers and users of the solutions developed. Compared to traditional engineering education focusing on the development within the technical domain, the socio aspects of the system hence play a larger role. This means that the design and implementation of the courses for many teachers is considered rather unfamiliar and quite demanding (Duderstadt, 2008; Galloway, 2008).

Teachers ability to handle the transition from being the subject expert to becoming the facilitator of student teams learning and peer learning process is fundamental. When student teams are addressing real-life situations, it will by default involve a number of failures and surprises that require handling and continuous learning process. A highly effective teaching and learning depend on a teacher's ability to design learning opportunities where students participate in activities that lead to an understanding of learning as a process and mistakes as a natural part of this process (Carnell, 2007) In addition, conflicts among team members with different backgrounds and from different disciplines because of real or perceived differences and viewpoints will most likely also be present. The development of coaching skills emerge as potentially valuable since coaching is a direct, timeappropriate interaction between a coach (teacher) and coachée (student) aimed at developing competence and improving performance in the coachée (Wisker et al., 2003). Studies from the management field suggest that developing coaching skills can contribute to leadership effectiveness (Finn et al., 2007). Schön (1988) can be described as a forerunner of promoting the value of using coaching in higher education. In contrast, to the empirical interest on coaching skill development in the management and executive area (e.g., Finn et al., 2007) there is however a scarcity of studies targeting to understand the role of coaching in the higher education space. In one of the few studies 
performed, it was found that when teaching assistants were trained in coaching, their students reported higher team functioning and productivity (Sargent et al., 2009). Understanding how teachers can train their ability to facilitate collaboration and learning in student teams addressing real-life sustainability challenges emerges as an important area to investigate.

\section{Research design and methods}

The target of the investigation described in this paper is a teacher training implemented in three universities; at KTH in Sweden, at Botho University in Botswana and at Strathmore University in Kenya. The teachers that were trained came from different disciplines (e.g. engineering, humanities, economics), had different academic degrees (from $\mathrm{PhD}$ to full professors) and were teaching students in their final years (bachelor and master level). The aim of the training is to improve teacher's ability to facilitate multi-disciplinary and multi-cultural students' teams learning and collaboration skills by making teachers aware of the challenges facing teams addressing complex challenges, and to train their facilitation skills. The training is dominated by practical exercises intertwined with shorter theory sessions to support experiential learning, following the first part of the cycle Concrete experience Reflective observation - Abstract conceptualization - Active experimentation (Kolb, 1984), and was developed and implemented by the two authors in collaboration, A more detailed description of the design and content of the teaching training is found below in Section 4.

The first training occasion took place at Botho University, and was run in two half days. The selection of participants was made from an open call to teachers who intend to develop challenge driven project courses, with a clear interest to develop her/his pedagogical skills. The training was then run at Strathmore University in Nairobi, Kenya, using the same selection criteria. Here the training took place during one day. The third time the training was run for six hours at KTH as a part of a larger teacher training program for challenge driven education developed by the GDH. The selection of participants was made based of their general interest in developing skills for challenge driven education. Finally, the training module was run at KTH for three hours in an extremely diverse group of international academics within a program called Enhancing Higher Education.

Written feedback from participating teachers was collected in conjunction to the training occasions. In addition, informal feedback was collected by notetaking during each training occasion. Three rounds of written feedback were collected. Firstly, each participant was asked to send in a short description on his/her earlier experiences from working with student teams and what challenges they face as teachers when facilitating student projects. Secondly, feedback on the course content and format as well as key learning insights was collected in direct conjunction to the ending of each training occasion. Thirdly, a request to answer what key learning insights they found most useful in their own teaching practice was sent out to the three first groups one year after their training. Analysis of the data was made by open coding of the feedback by the two authors individually to identify similarities and differences as well as emerging themes on what seem to be critical elements when developing teachers' abilities to facilitate collaboration and learning in student teams addressing real-life sustainability challenges.

\section{Designing a new teacher's training}

The content of the training was developed in parallel to its format in order to meet the defined outcomes i.e. to increase teachers understanding of the challenges facing teams addressing complex societal challenges and to train their facilitation skills. The training was divided into seven themes that were modularized to enable an adaption of the training to the actual resources and time available in a certain setting. In the design of the training, it was early on decided to base the training on different types of exercises and ways of presenting the content. The overall design of each of its themes or modules follows a sequence of 1) experience through practical exercises 2) reflections and discussions and 3) providing motivation/theory. Each module relates to a key issue present when facilitating student teams addressing open-ended and complex challenges. The issues as well as examples of how to handle these, were identified through a workshop with teachers experienced in facilitating such student projects (i.e. proven practices) and by reviewing relevant literature. The issues were found to 
be related to the openness and complexity of the task, the multi-disciplinary and multi-cultural team setting, and to the changes in the teacher and student roles that these projects demand. In addition to the workshop with experienced teachers, an experienced management coach was consulted to receive advice on how to train coaching skills. The seven modules are described in detail below:

\section{Module 1: The changed teacher role}

Practical exercise/input: The participating teachers were asked to deliver a one-pager of their experiences from handling student teams and what challenges they expect when introducing challenge driven education in their courses.

Reflection and discussion: The feedback from the teachers were summarised and presented to the group.

Experiences (successes and failures) were shared openly in the group.

Main motivation/theory: A compiled list of changes in the role based in proven practices and review of literature, see Figure 2.

Module 2: The changed student role

Practical exercise/input: Performing brainstorming (both on an individual and on a group level) around potential reactions from the students when the teacher role is changed.

Reflection and discussion: Sharing and reflections on the outcome from the brainstorming- challenges and opportunities when introducing challenge-driven education courses.

Main motivation/theory: Literature related to challenge-driven education.

\section{Module 3: To start and end open-ended projects}

Practical exercise/input: The group was given the task to define principles on how to behave and interact during the teacher training as a way to practice the identification and use of 'rules of the game'.

Reflection and discussion: Shared reflections and discussions on the value of early on identifying preferred behaviours (i.e. 'rules of the game') in open-ended projects.

Main motivation/theory: Literature related to design thinking.

Module 4: Understanding group dynamics

Practical exercise/input: Groups of a minimum of 6 individuals are given the task to solve a geometric puzzle. The aim with the exercise is to show how anyone in a team can contribute or prevent that a group reach intended goals - and that everyone is needed to reach a solution and have to understand the whole to be able to contribute to the solution. One or several group members take on the role as observers.

Reflection and discussion: The observers start with presenting their findings of how their group worked and then everyone continues with sharing their experiences from the exercise.

Main motivation/theory: Literature related to group dynamics and creative climate.

Module 5: Handling conflicts and building trust

Practical exercise/input: Watching a YouTube video clip discussing strategies for handling conflicts and building trust.

Reflection and discussion: Reflections on the video and sharing of experience from the use of strategies to avoid and/or overcome conflicts in student teams and for building and maintaining trust.

Main motivation/theory: Literature related to managing conflicts and building trust in teams and among stakeholders.

\section{Module 6: Coaching}

Practical exercise: Training coaching strategies in groups of three. Everyone alternates between acting coach, coachée and observer. The coachée selects an issue related to her/his teaching role and the coach is given the task to support the coachée to define, reflect, develop and solve his/her challenge by asking curious questions with full attention. After each coaching session, the observer start with sharing hers/his findings with the coach and coachée.

Reflection and discussion: Sharing of the outcomes from the groups - perceived strengths and challenges.

Main motivation/theory: Literature related to coaching as a structured dialogue. The motivation is introducing this module followed by a show-and-tell by the trainers.

\section{Module 7: Peer coaching}

Practical exercise: The group was divided into smaller groups of 4-5 members that coached each other's suggestions on how to support the development of challenge driven education courses at their 
university. This was followed by an exercise in pairs to experience the difference in making use of 'Yes, but' and 'Yes, and' as a mean to create an open climate and to open up for contributions from all team members.

Reflection and discussion: Sharing of the experiences from the two exercises and how they could be used in existing or planned courses.

Main motivation/theory: Literature related to peer to peer processes.

Two additional important elements in the teacher training were the use of ice-breakers to enable a change in perspectives and level of energy when shifting between different modules and a careful use of how the space was used e.g. shifting how attending teachers were seated and the size of the groups during exercises and reflections to create an awareness of the importance of variation to stimulate the learning and collaboration in a team.
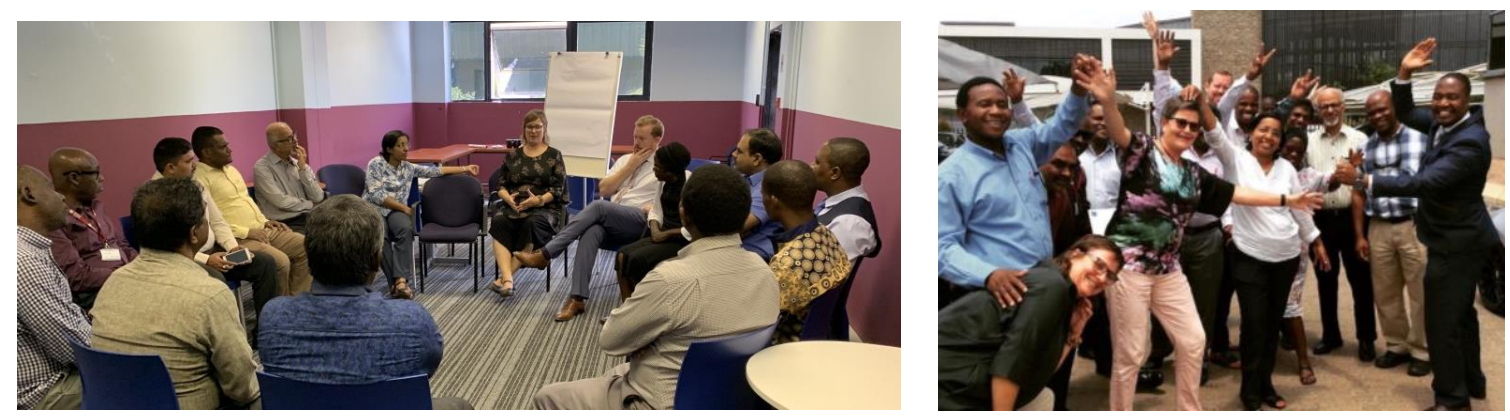

Figure 1.

The training always started with the module on the changed role for the teacher, (see a summary of the general changes discussed in Figure 2) and depending on the length available for a specific training session, both the number and the order of the modules in use differed.

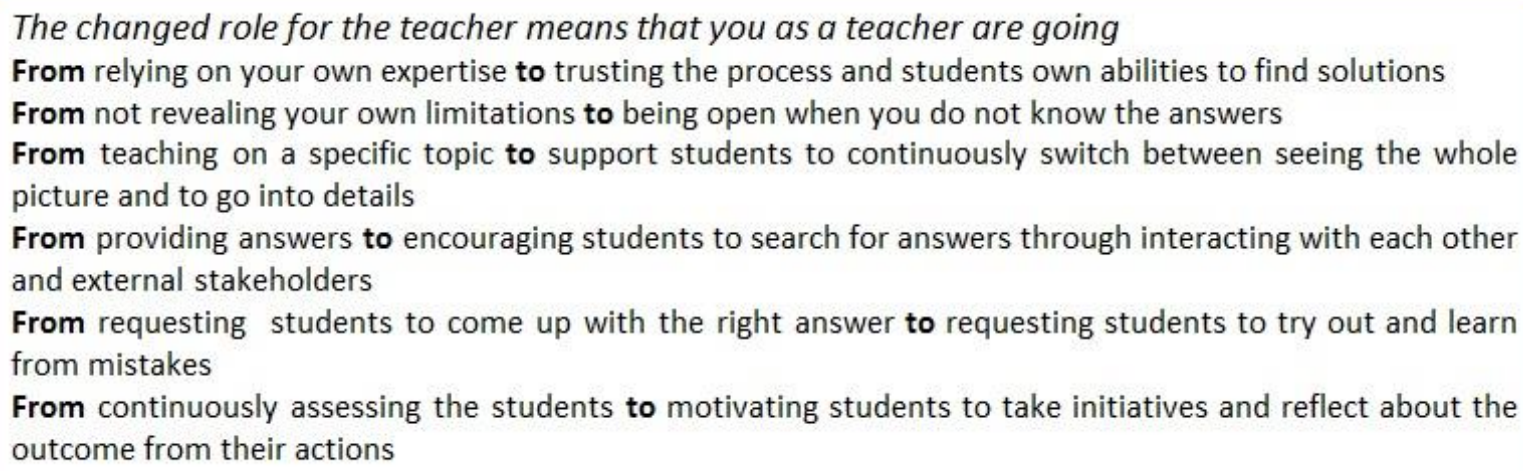

Figure 2. A summary of implications from challenge driven education on the teacher role

\section{Input and feedback from participants in teacher training}

When the feedback from participating teachers were analysed a large number of commonalities as well as some differences emerged. Both regarding what challenges teachers are experiencing or foresee when changing their teacher role and when it comes to what learning from the training that teachers found the most important and useful in practice.

\subsection{Challenges facing teachers and students}

In the discussions and reflections on what the teachers foresee to be most challenging both for themselves and for their students when changing their roles from being an expert to becoming more of a facilitator, the question of legitimacy is highlighted. For committed and engaged students, taking on a more facilitating role put demands on the teachers "to be very versatile and knowledgeable on quite a number of areas" which is considered a challenge in itself. Since the majority of students expect the 
teachers to be the one that provides a straight answer, a more facilitating and coaching approach is expected be viewed as both confusing and frustrating. "Students may feel lost at first as the advice they get is not what they expect". Teachers refer to that the students will find it 'strange' with so many questions and most probably will find it difficult or even resist to adapt. An important reflection from one of the teachers is the challenge he is facing in making students taking ownership of their own learning process: "Our students have a lot of potential, but they don't take responsibility of their learning so if we could bring a change in that we can create magic here."

On the other side, many of teachers highlight that by making use of coaching and peer-coaching, the students most probably in the long run will find it rewarding and motivational. "Students will think that you're seriously concerned with their issue ...They will feel safe and willing to express their opinions without feeling judged". A teachers more facilitating role, is expected to support student gaining confidence to talk, ask questions and participate more in classes. In the long-run, the majority of teachers felt sure that it will lead to a more inclusive and creative environment. Some teachers also point to the challenge associated to the role that the teachers have in also being the change agent in this process. How to avoid "to give the student the fish they always demand but rather teach how to catch fish".

During the discussion on conflict management, several teachers highlighted that how conflicts in the classroom is handled is to a large extent influenced by the general culture on how to deal with conflicts (e.g. avoiding or confronting). Further, that it is important to define what conflict means as opposed to difference of opinions as the term may evoke very different responses. In general, discussing and sharing experiences from conflicts with or between students is seldom performed among the teachers. During one of the training occasions, a teacher shared a personal experience from failing to cope with a conflict among students which led to a number of similar stories from the other teachers on not being able to handle conflicts and a discussion on potential useful strategies.

The differences among the teachers on what was considered to be challenges between the settings where the training took place were few. One difference identified was that in the African context a general lack of student's engagement in project work was highlighted. Students socio-economic situation leading many of them having to work full-time in parallel to their studies and "the traditionalist perspective that still haunts the education system" was described to act as barriers to student's motivation and initiative taking abilities for working in teams. as the majority of teaching is class-room based and focused on assessments and evaluations rather than on creating a variation of learning activities. The student's reactions on teachers use of a more facilitating or coaching approach was raised as a concern among some of the teachers at the African university. By avoiding to providing clear answers the legitimisation of the teacher role may be questioned and it may lead to reduce trust and increase insecurities in the teams.

\subsection{Key learning insights}

Surprisingly few of the teachers had experiences from the exercises and core concepts provided in the modules. Both the content and the format were considered new and valuable and the training was described to have acted as a an 'eye-opener' for many participants. In general, all teachers found the training very inspiring and they did not differ much when it came to what they highlighted as most useful in practice; the majority of teachers brought forward the module on coaching and how coaching can be a tool to effectively support student engagement and proactivity. "Making use of questions during facilitation as opposed to provision of answers and the suspension of judgement is important". "Facilitating and coaching will significantly impact students' innovativeness, finding their own solutions to their problems and learning to learn". "My primary insight concerns how to engage students and how facilitating learning is more productive for the student and facilitator as well". Also, the role of peer coaching was raised as an important concept. Other teachers pointed to the importance in having learnt that coaching or facilitating is a structured communication that can be trained through rather straight forward exercises. Also, how the exchange of simple words such as making use of "and" and not "but" in discussion can make a big difference in how creative and constructive a dialogue becomes was highlighted by several of the teachers. 
Another commonality when it comes to key learnings was the importance on understanding team conflict resolution or management. "In dealing with conflicts you need to be compassionate and curious... and being open to address the conflicts, talk about issues". Also, how the presence of team conflicts can be a sign of progression was highlighted as a key learning as well as how to agree to disagree can be an important principle in certain situations. To understand the value of creating trust in teams emerged as an important learning from the feedback received: "The importance of transferring trust to students and believing in their abilities to find solutions to problem". "Trust is key and starts with the small shared things like open communication and punctuality". In addition, how the surfacing and management of conflicts is connected to the creation of trust was also found to be considered a key learning for some of the teachers.

Several of the teachers also pointed out the power in creating variations in how to teach i.e. teaching with different styles e.g. using slides, videos, exercises, ice breakers, group discussions in various settings etc. in order to make lessons interesting and making the students more engaged and motivated. "Variations in delivery of the lessons i.e. the different exercises and reflections. The exercises may seem simple but are very interesting!" Not the least to consider the use of practical exercises were highlighted as an important learning: "By engaging the students in thought provoking exercises, they ultimately develop a habit of generating/provoking solutions on their own /from their colleagues, thereby owning them." Several of the teachers expressed that they found the design of the training very useful itself as they considered it to be an example on how to design and deliver according to the principles and core concepts taught. Many teachers expressed how the training had increased their self-confidence in starting to experiment with the use of alternative teaching styles.

A few of the teachers provided feedback one year after the training had taken place. Some of the teachers presented examples on how they had introduced a much more varied or mixed way of teaching to encourage interactivity and improve student engagement. They found it to have a huge impact on student's innovation capacity and critical thinking as well as self-confidence. Another teacher describes how he has come to understand the importance of collaboration: "....collaboration among teachers, among students and among students and teachers and collaboration with stakeholders". Prior to the workshop, I did not value this (collaboration) that much. The results after making use of the workshop have been excellent." The latter is reflected also in another teacher's example on how he "have gained confidence in advising my students on innovation in most of my courses. My teaching has nowadays changed to become highly practical. Additionally, I have slowly moved to an approach where I co-teach with fellow faculty or invite them during my student presentations so as to enrich the class experience. The students' feedback about this was amazing and I will continue doing it". In addition, one of the teachers described how he had started to train his students in peer-coaching and how it facilitated the team work.

\section{Discussion}

The design of the training was found to work surprisingly well despite very different settings and independent on the order of the modules in use and its length in time. An indicator to this conclusion beyond the commonalities in the feedback from participating teachers, is the questions raised by the participants during the training - questions by the end of one module was found to relate very well to the content in the subsequent module.

When analysing the feedback, it becomes clear that training on coaching skills stands out as particularly useful. The experience from participating in the coaching and the peer-coaching exercises is highlighted as key learnings for almost every participant. To be able to experience coaching as a structured and rather straight forward way of communicating was considered an eye-opener to many of the participants and something they considered easy to start practice in their own teaching. There is an increased interest in both research and practice on the role of coaching in higher education and an emerging awareness that simply copying how coaching is used in the business concept need to be challenged since the end-goal differ (Sargent et al., 2009). Schön (1988) emphasizes that when teacher and students have a productive coaching dialogue they function also as researchers, investigators of a situation, and are able to create new knowledge. Exploring and experimenting to create new knowledge can be considered key activities when student teams are addressing complex sustainability 
challenges. Societal challenges are characterised not only by the many different stakeholders involved and their different needs and many times diverging norms and values but by the interconnectedness of several sustainability challenges leading to a need to manage conflicting goals and trade-offs. Developing teachers coaching skills can hence be considered crucial when aiming to improve collaboration and innovation in these teams. The same is true for peer-coaching since a peer-to-peer process enables students becoming explicit about what they do and do not know in a more susceptible way than with someone in a position of authority (Topping 2005). In addition, it has the potential to both expand and verify the coach as well as the coachee's knowledge (Ladyshewsky 2006). By increasing the awareness of what the knowledge gaps are and at the same time help to develop the knowledge base, peer to peer processes can be argued to be particularly effective when dealing with high levels of complexity, uncertainty and ambiguities. Based on the insights from the investigation of the training in this paper, the role of coaching and what coaching approaches are particularly useful for teachers facilitating student teams addressing complex societal challenges is suggested to require increased attention. Adams et al. (2016) in-depth investigation of design reviews in higher education shows the many nuances of how coaching can be performed to guide and stimulate creativity and learning for students. It illustrates the value in building knowledge based in contexts outside the business and management arena where the end-goal is competitiveness or increased performance rather than exploring to create new knowledge.

The western model of education is dominating also in African countries which may explain the limited number of differences in the feedback from the teachers identified in the analysis. The western education model when applied in an African context means however that the education is more tailored towards functioning in a Western context and less suitable in addressing the basic socioeconomic problems in African countries and there is a tendency to make use of Western curriculum templates without a rigorous analysis of their relevance (Tshabangu-Soko and Caron, 2012). This needs to be taken in consideration also when developing teacher training for different settings. The feedback from the teachers highlighted the value in basing the training on practical exercises and in varying teaching styles, how space is used and groups composed as it inspired them to experiment and try out new ways of teaching themselves. This highlights the importance of designing training where new experiences can be enabled besides creating room for sharing previous experiences. The variations were also experienced as something engaging and that feeling of engagement created an understanding of how valuable such approach may be to also motivate students to take a larger responsibility for their learning; something that the teachers from the two African universities brought forward as particularly important in their own contexts.

\section{Conclusions and recommendations for practice}

Universities have a key role in developing the knowledge and competences required to meet the UN sustainable development goals (UN 2015; UNESCO, 2017). Systematically improving teacher's ability to facilitate collaboration and learning in multi-disciplinary and multi-cultural student projects is still an exception rather than a routine in practice despite such skills can be considered critical in order to develop students' key competences for sustainable development (Rieckmann, 2010). We are in this paper able to provide some new insights on how to design and implement teacher training enabling teacher's ability to facilitate collaboration and learning in student teams addressing complex societal challenges. We show that it is possible to get rather quick improvements in a rather efficient way from a time and resource perspective. Our investigation points to the importance of initiating additional studies on how coaching can become a skill that takes place not only in executive and management training but form part also of higher education pedagogics. In addition to the presentation of the content and format of a teacher training, we propose a number of elements that emerge as particularly valuable. In the spirit of the Design Society, we also suggest the following four design principles to be taken in consideration:

1. Design for variation. Make sure to design the training to include different teaching styles, pedagogics and exercises. Take in consideration also how to vary the physical space, group composition and how time is managed. 
2. Design for experiential learning. Search for experiments and exercises that give immediate learnings - the power of practical experience includes a potential of a long-lasting learning.

3. Design for coaching. Provide opportunities for teachers to train their coaching skills. Both on an individual and on a team level (peer-coaching).

4. Design for collaboration. Create a safe and empowering space to enable teachers to share experiences also from less successful occasions and bring light to the importance in managing group dynamics and team conflicts.

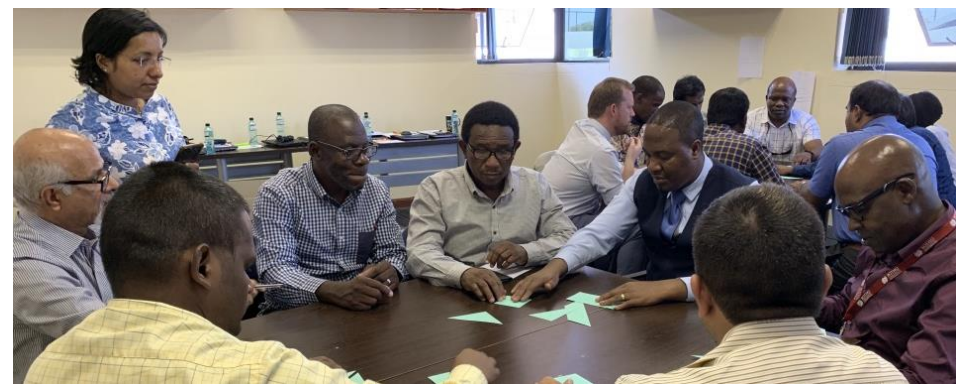

Figure 3.

\section{Study limitations}

This study is based on the evaluation of one teacher training design in four different settings and hence additional studies are required in order to make any general conclusions on what is important when it comes developing teacher's ability to facilitate collaboration and learning in open-ended student project.

\section{Acknowledgement}

This research was supported by Global Development Hub at KTH Royal Institute of Technology, Mats Berglund and Vinnova. We are thankful to our colleagues Maria Stockhaus and Gunilla Ölundh Sandström who provided expertise that assisted us in the design of the teacher training presented and evaluated in this article.

\section{References}

Adams, R. et al. (2016), "Characterizing the work of coaching during design reviews", Design Studies, Vol. 45, pp. 30-67. http://docs.lib.purdue.edu/enepubs/17

Carnell, E. (2007), "Conceptions of effective teaching in higher education: extending the boundaries", Teaching in Higher Education, Vol. 12 No. 1, pp. 25. https://doi.org/10.1080/13562510601102081

Dreu, C.K.W. and Weingart, L.R. (2003), "Task Versus Relationship Conflict, Team Performance, and Team Member Satisfaction: A Meta-Analysis", Journal of Applied Psychology Copyright 2003 by the American Psychological Association, Inc, Vol. 88 No. 4, pp. 741-749.

Duderstadt, J.J. (2008), Engineering for a Changing World - A Roadmap to the Future of Engineering Practice. Research, and Education, The Millennium Project, The University of Michigan.

Dutson, A.J. et al. (1997), "A Review of Literature on Teaching Engineering Design Through Project- Oriented Capstone Courses", The Journal of Engineering Education, Vol. 86 No. 1, pp. 17-28. https://doi.org/ 10.1002/j.2168-9830.1997.tb00260.x

Finn, F.A., Mason, C.M. and Bradley, L.M. (2007), "Doing Well with Executive Coaching: Psychological and Behavioral Impacts", In: Solomon, G. (Ed.), Proceedings Academy of Management 2007 Annual Meeting Proceedings: Doing Well By Doing Good, pages, Philadelphia, United States, pp. 1-34.

Galloway, P.D. (2008), The 21st-Century Engineer: A Proposal for Engineering Education Reform, ASCE Press.

Högfeldt, A.-K. et al. (2018, April), "Understanding Engineering Education Change With the Introduction of Challenge Driven in Tanzania", In: In Global Engineering Education Conference (EDUCON), IEEE, pp. 1341-1349, oai:DiVA.org:kth-231664.

Kolb, D. (1984), Experiential Learning: experience as the source of learning and development, Prentice Hall, Englewood Cliffs, NJ. p. 21

Kolmos, A. et al. (2008), "Participation on Challenge Based Learning", International Journal of Engineering Education, Vol. 34 No. 1, pp. 187-200, Facilitation in a PBL environment, Aalborg University 2008. 
Ladyshewsky, R.K. (2006), "Peer Coaching: A constructivist methodology for enhancing critical thinking in postgraduate business education", Higher education research and development, Vol. 25 No. 1. https://doi.org/10.1080/13600800500453196

Magnell, M. and Högfeldt, A.-K. (2015), Guide to challenge-driven education, ISBN: 978-91-7595-089-1, KTH, Stockholm. https://www.kth.se/social/group/guide-to-challenge-d/

Norell Bergendahl, M. et al. (2018), Challenge Driven Education for SustainablenGlobal Development - KTH Global Development Hub Position Paper, KTH Royal Institute of Technology, Stockholm, Sweden.

Rieckmann, M. (2010), "Future-oriented higher education: Which key competencies should be fostered through university teaching and learning?", Futures. https://doi.org/10.1016/j.futures.2011.09.005

Rosén, A. et al. (2018), “Connecting North and South through Challenge Driven Education”, In: Proceedings of the 14th International CDIO Conference, Kanazawa, Japan, oai:DiVA.org:kth-240881.

Rådberg K.K et al. (2018), "From CDIO to challenge-based learning experiences - expanding student learning as well as societal impact?", European Journal of Engineering Education, Vol. 45 No. 1, pp. 22-37. https://doi.org/10.1080/03043797.2018.1441265

Sargent, L.D., Allen, B.C. and Frahm, J.A. (2009), "Enhancing the experience of student teams in large classes. Training teaching assistants to be coaches", J of Management Education. https://doi.org/10.1177/ 1052562909334092

Schön, D.A. (1988), "Designing: Rules, types and worlds”, Design Studies, Vol. 9 No. 3, pp. 181-190. https://doi.org/10.1016/0142-694X(88)90047-6

Topping, K. (December 2005), “Trends in peer learning”, Educational Psychology, Vol. 25 No. 6, pp. 631-645. https://doi.org/10.1080/01443410500345172

Tshabangu-Soko, T.S. and Caron, R.M. (2012), "The Western Model of Higher Education: Applications and Implications for African Development", In: Caron, R. (Ed.), Educational Policy in the Twenty-first Century, Nova Science Publishers, Inc., Hauppauge, N.Y., pp. 37-47.

UN. (2015), "Transforming our world: the 2030 Agenda for Sustainable Development", Resolution, Vol. 70 No. 1.

UNESCO. (2017), Education for Sustainable Development Goals - Learning Objectives.

Wiek, A., Withycombe, L. and Redman, C.L. (2011), "Key competencies in sustainability: a reference framework for academic program development", Sustain Sci, Vol. 6, pp. 203-218. https://doi.org/10. 1007/s11625-011-0132-6

Wisker, G. et al. (2003), "From Supervisory Dialogues to Successful PhDs: Strategies Supporting and Enabling the Learning Conversations of Staff and Students at Postgraduate Level", Teaching in Higher Education, Vol. 8 No. 3, pp. 383-397. https://doi.org/10.1080/13562510309400 